\title{
A influência sócio-familiar no comportamento alimentar de pacientes obesos
}

\author{
The socio-family influence in the feeding behavior of obese patients \\ La influencia sociofamiliar en el comportamiento alimenticio de pacientes obesos
}

\begin{abstract}
RESUMO
Objetivo: Compreender de que forma a família, como instituição social, influencia no comportamento alimentar de pacientes obesos. Método: Pesquisa de natureza qualitativa, realizada no laboratório de avaliação psicológica de um hospital escola na cidade de Recife-PE. A coleta dos dados se deu por meio de entrevista e a análise foi realizada utilizando a Análise temática de conteúdo. Participaram 10 pacientes, a maioria do sexo feminino. Resultado: Os resultados revelaram quatro categorias temáticas relativas aos aspectos que circundam a dinâmica familiar dos sujeitos participantes e seus comportamentos alimentares, considerando questões simbólicas. Conclusão: As dinâmicas de gênero, os processos de alimentação, escolha, consumo e a preparação da comida, podem resultar de influências familiares desenvolvidas através dos processos de identificação, aprendizagem, interiorização e repetição das experiências vivenciadas nos ambientes de convivência, denotando o caráter simbólico da comida e seu papel na vida dos sujeitos, adicionando subjetividade e afetividade à esta forma de nutrição.
\end{abstract}

DESCRITORES: Comportamento Alimentar; Família; Obesidade..

\section{ABSTRACT}

Objective: To understand how the family, as a social institution, influences the eating behavior of obese patients. Method: Qualitative research, carried out in the psychological assessment laboratory of a teaching hospital in the city of Recife-PE. Data collection took place through interviews and the analysis was carried out using thematic content analysis. Ten patients participated, most of them female. Results: The results revealed four thematic categories related to the aspects surrounding the family dynamics of the participating subjects and their eating behaviors, considering symbolic issues. Conclusion: Gender dynamics, the processes of eating, choosing, consuming and preparing food, may result from family influences developed through the processes of identification, learning, interiorization and repetition of experiences in living environments, denoting the symbolic character of food and its role in the subjects' lives, adding subjectivity and affectivity to this form of nutrition.

DESCRIPTORS: Feeding behavior; Obesity; Family.

\section{RESUMEN}

Objetivo: Comprender cómo la familia, como institución social, influye en la conducta alimentaria de los pacientes obesos. Método: Investigación cualitativa, realizada en el laboratorio de evaluación psicológica de un hospital universitario de la ciudad de Recife-PE. La recolección de datos se realizó a través de entrevistas y el análisis se realizó mediante análisis de contenido temático. Participaron diez pacientes, la mayoría mujeres. Resultados: Los resultados revelaron cuatro categorías temáticas relacionadas con los aspectos que rodean la dinámica familiar de los sujetos participantes y sus conductas alimentarias, considerando cuestiones simbólicas. Conclusión: Las dinámicas de género, los procesos de comer, elegir, consumir y preparar alimentos, pueden resultar de las influencias familiares desarrolladas a través de los procesos de identificación, aprendizaje, interiorización y repetición de experiencias en los ambientes de vida, denotando el carácter simbólico de la comida y su rol en la la vida de los sujetos, agregando subjetividad y afectividad a esta forma de nutrición.

DESCRIPTORES: Comportamiento alimenticio; Familia; Obesidad.

RECEBIDO EM: 28/06/2021 APROVADO EM: 18/01/2022

\section{Renata Teti Tibúrcio Maia}

Psicóloga no Instituto de Medicina Integral Professor Fernando Figueira (IMIP) e docente na Faculdade Pernambucana de Saúde (FPS). Graduada pela Universidade Federal de Pernambuco, Mestra em Psicologia da Saúde e especialista em Psicologia Clínica e Hospitalar.

ORCID: 0000-0003-0798-7226

\section{Mônica Cristina Batista de Melo}

Psicóloga no Instituto de Medicina Integral Professor Fernando Figueira (IMIP) e docente na Faculdade Pernambucana de Saúde (FPS), compondo o quadro da graduação, pós-graduação e mestrado da instituição. Graduada pela Universidade Católica de Pernambuco (UNICAP), especialista em Psicologia Hospitalar, mestre e doutora em Saúde Materno Infantil e Pós-doutorado em Ciências da Saúde. 


\section{INTRODUÇÃO}

0 olhar para o sobrepeso e a obesidade na sociedade atual vem sendo ampliado, na medida em que estas condições se tornaram um aspecto importante no estabelecimento da busca pela saúde pública. Segundo dados da pesquisa Vigitel, divulgada pelo Ministério da Saúde no ano de 2020, 55,4\% dos brasileiros adultos estavam acima do peso e $20,3 \%$ dessa população encontra-se em estado de obesidade. 1

A Organização Mundial de Saúde (OMS) define o sobrepeso e a obesidade como um anormal ou excessivo acúmulo de gordura que pode afetar a saúde e aborda a obesidade como uma questão complexa que envolve dimensões sociais e psicológicas, afetando sujeitos de diversas faixas etárias e classes econômicas. 2

A sociedade atual vem expressando sua noção de alimentação entrelaçada por aspectos culturais onde o alimento sai do lugar de nutriente para promover prazer sensorial, ser um ritual, uma linguagem simbólica que veicula significados. Nessa perspectiva, o sujeito se alimenta conforme o meio a que pertence e conforme a sociedade em que se insere, seu grupo social, estabelecendo distinções e marcando fronteiras precisas. 3,4

Sendo assim, entende-se comportamento como uma função que une fatores filogenéticos e ontogenéticos, que operam nas interações de um dado organismo dessa espécie com seu ambiente. Nesta perspectiva, o comportamento alimentar humano reflete interações entre o estado fisiológico, psicológico e as condições ambientais de um dado indivíduo, caracterizando os alimentos ou tipo de alimentação que este consome rotineiramente e repetidamente no seu cotidiano. $5,6,7$

Sabe-se que a instituição familiar, mediadora entre sociedade e indivíduo, fornece para ele sua primeira identidade social, sendo fonte de constituição de sua personalidade e seu comportamento. A família é um dos principais exemplos de instituição social, e é dentro e através dela que o sujeito aprende sobre o mundo, a se situar nele e
A Organização

Mundial de Saúde

(OMS) define

\section{o sobrepeso e a}

obesidade como

um anormal ou

excessivo acúmulo

de gordura que pode

afetar a saúde e

aborda a obesidade

como uma

questão complexa

que envolve

dimensões sociais

e psicológicas,

afetando sujeitos

de diversas faixas

etárias e classes

econômicas. sobre sua educação nutricional.8,9,6

Nas práticas alimentares, que vão dos procedimentos relacionados à preparação do alimento ao seu consumo, a subjetividade veiculada inclui, dentre outros, a identidade cultural, a condição social, a religião e a memória familiar. A alimentação, enquanto prática se origina no universo doméstico, estando envolta no convívio familiar e social, vinculada na maioria das vezes à figura da mãe e da mulher e, portanto, atrelada a uma referência afetiva. 10

Diversos estudos já consideram a família como fator influente no processo de alimentação do sujeito, demandando pesquisas que se adentrem nas bases desta relação, identificando determinantes que se projetaram no comportamento alimentar durante a vida adulta. 6, 7, 10,11,12Diante desta perspectiva, este estudo teve como objetivo explorar de que forma a família, como instituição social, influencia no comportamento alimentar de pacientes obesos.

\section{MÉTODO}

Trata-se de um estudo descritivo, de base qualitativa, visando compreender possíveis contribuições sociais e familiares na construção e desenvolvimento do comportamento alimentar de pacientes obesos, adentrando na análise dos fenômenos segundo a perspectiva dos sujeitos, ou seja, dos participantes da situação em estudo, tendo como paradigma uma realidade construída socioculturalmente.13,14 Foi realizado no Laboratório de Avaliação Psicológica pertencente ao Ambulatório Geral de Psicologia de um hospital escola da região metropolitana do Recife, no período entre maio e agosto de 2016.

A amostragem desta pesquisa tomou como preditor para a finalização da coleta a saturação do conteúdo, sendo entrevistados um total de 10 pacientes. Foram inclusos no estudo os pacientes de ambos os sexos, maiores de 18 anos, em acompanhamento psicológico pré e pós cirurgia bariátrica que aceitaram participar da pesquisa. Foram excluídos da pesquisa os pacientes menores de 18 anos ou que apresentavam comprometimentos físicos e/ou psicológicos que 
impossibilitavam a compreensão das questôes elaboradas e/ou a compreensão das respostas por parte do pesquisador. Os dados foram coletados mediante a aplicação de um questionário sociodemográfico e de uma entrevista, que foi gravada, mediante autorização prévia dos sujeitos.15,16

Após a construção dos dados da entrevista, o conteúdo de áudio gravado foi transcrito e submetido ao processo de análise de conteúdo, levando à elaboração de quatro categorias temáticas para a discussão, buscando compreender o sentido e significação da fala dos entrevistados16, 17. Os participantes foram identificados em ordem numérica, mantendo a confidencialidade e o sigilo. Os sujeitos foram convidados a participar da pesquisa, de forma voluntária, sendo esclarecidos os aspectos éticos e detalhes da pesquisa, com a leitura e coleta das assinaturas a partir do Termo de Consentimento Livre e Esclarecido. A pesquisa seguiu as orientações da resolução 510/16 do Conselho Nacional de Saúde (CNS) e foi aprovada pelo Comitê de Ética em Pesquisa em Seres Humanos do IMIP (CAAE: 54767816.6.0000.5201).

\section{RESULTADOS E DISCUSSÃO}

Foram entrevistados 10 pacientes, com faixa etária entre 23 e 36 anos, sendo nove do sexo feminino, dois deles estando em processo de acompanhamento pós-bariátrica e os outros oito em acompanhamento pré-cirúrgico, trazendo em seus discursos conteúdos, as quais foram estruturados em quatro categorias temáticas relativas aos aspectos que circundam a dinâmica familiar dos sujeitos participantes e seus comportamentos alimentares, considerando seus aspectos simbólicos.

Categoria 1: As Dimensões afetivas do processo alimentar

Nas entrevistas, os participantes comentaram acerca de suas vivências nas famílias de origem com entonações afetivas que circundam o ato de comer e os significados em torno deste, revelando especificidades de um comportamento alimentar que se origina na infância, tendo como plano de
A partir das falas é possível supor que o ato alimentar na dinâmica familiar pode representar

o cuidado no sentido de saciar algo que falta. Esse ato, pode gerar no outro a busca por um preenchimento numa perspectiva cíclica que pode se estender até a vida adulta tendo o papel da mulher como

preponderante

na preparação da

comida18 uma vez

que, o espaço da

cozinha fundo o grupo familiar nos quais estavam inseridos, como podemos observar nas falas a seguir:

Sujeito 1: (...) a minha infância eu chorava e meus pais me enchiam de comida; eu já digo quando bebê, que era uma história engraçada, que quando eu tinha fome, quando o leite não tava pronto, minha tia cessava farinha e colocava aquele mingau grosso na minha boca, era mingau e água, mingau e água até eu estar saciada. Eu fui crescendo... às vezes eu comia, comia, vomitava e voltava a comer.

Sujeito 6: (...) Minha mãe sempre cozinhou bem tudo, aí eu comia bastante, comia e ia dormir, meu hábito era esse, que eu comia bastante mesmo. (...) lá em casa todo mundo comia tudo diferente, não é a mesma coisa, todo dia é uma coisa diferente, porque minha mãe para fazer o gosto de todo mundo aí faz uma alimentação para cada um...

A partir das falas é possível supor que $o$ ato alimentar na dinâmica familiar pode representar o cuidado no sentido de saciar algo que falta. Esse ato, pode gerar no outro a busca por um preenchimento numa perspectiva cíclica que pode se estender até a vida adulta tendo o papel da mulher como preponderante na preparação da comida 18 uma vez que, o espaço da cozinha, 19 é o espaço de articulação entre a natureza e a cultura, onde o protagonismo materno é detentor de um saber culinário que expressa características pessoais e culturais especificas à cada família.18

As falas nos remetem também a historicidade familiar, onde a figura materna promove as vivências alimentares associando a alimentação à afetividade e proteção. 20 Tal vivência transforma o alimento em uma linguagem e abre espaço para possibilidades de comunicação entre mãe e filho, gerando prazer e satisfação familiar. 21, 22 A mulher, ao assumir este protagonismo, encarrega-se da preparação do alimento, depositando neste um "tempero" próprio, dando à comida um gosto único, revelando dimensões culturais que marcam identida- 
des, evidenciando sentimentos e memórias do paladar.18 O gosto surge, então, para além de uma base biológica, mas também cultural e afetiva, 23 o gosto e a escolha pelo alimento se torna algo direcionado pela afetividade, algo familiar, projetando uma identidade dentro de um meio social, numa ideia de pertencimento. 18

Categoria 2. A perspectiva alimentar diante de um contexto de vulnerabilidade social

Observando os conteúdos das falas dos participantes a seguir, nota-se que os aspectos econômicos circundam o ambiente familiar, caracterizando o pertencimento à uma classe social definindo seu poder de compra que, junto às características culturais, interferem diretamente na escolha dos alimentos a serem consumidos.

Sujeito 1: Quando eu morava com meu pai, de início só ele trabalhava, aí o que ele poderia comprar só era aquela comida grossa que a gente de interior fala, aquela comida grossa que era feijão, cuscuz e raramente se entrava pão, bolacha, essas coisas de supermercado em casa. E ele trabalhou na agricultura e assim, sempre tinha um feijão verde, a galinha que a pessoa criava (...) minha mãe nas compras ela só podia comprar laranja e banana, não poderia comprar para 5 filhos uma variedade enorme de frutas e verduras, né? aí era tudo muito limitado.

Sujeito 2: (...) os tempos foram mudando, as coisas foram melhorando tal, as condições... Antes a gente tinha mais o básico, tá entendendo? O pão, feijão, o arroz... Só que aí as coisas foram melhorando, as condições financeiras, aí começou queijo de manteiga, toda semana queijo manteiga, queijo coalho, bolo e pronto...

Sabe-se que o espaço culinário familiar e o modo de comer se torna o primeiro sinal de diferença entre os indivíduos e as classes. 24 Assim, as estratégias alimentares que determinam meios de seleção e preparo, onde escolhem-se gêneros baratos e de alta densidade calórica, através dos quais a população de baixa renda consegue as ca-
Outro aspecto

observado nas

falas, sugere que

o pertencimento à

uma determinada

classe social não se

caracteriza como

estático. Diante de

possíveis mudanças

socioeconômicas,

abre-se espaço para

a ascensão social de

grupos familiares.

A partir deste

deslocamento, surge

a modificação dos

hábitos alimentares

diante do aumento

do poder de compra lorias de que necessita para sobreviver.25 Esse achado nos leva a pensar que estas estratégias de seleção podem tornar a dieta desta classe social monotonamente repetida, optando pelos alimentos considerados "fortes" no sistema classificatório alimentar, diante das condições socioeconômicas vivenciadas 24 , fazendo desta repetição um hábito que aprisiona o sujeito.

De acordo com a literatura, a fome, como o motor da busca pelo alimento, caracteriza o hábito alimentar e em um contexto de vulnerabilidade social, a partir de um critério de disponibilidade do alimento faz-se de objeto de desejo o alimento abundante, que enche e dá ao sujeito a sensação tão almejada de saciedade. $\mathrm{O}$ gosto passa também a ser determinado pela facilidade de encontrar o produto, sua capacidade de ser conservado e preparado e seu potencial de preenchimento.24 Os hábitos alimentares tornam-se dependentes, das possibilidades e condições de acesso aos alimentos. 22

Outro aspecto observado nas falas, sugere que o pertencimento à uma determinada classe social não se caracteriza como estático. Diante de possíveis mudanças socioeconômicas, abre-se espaço para a ascensão social de grupos familiares. A partir deste deslocamento, surge a modificação dos hábitos alimentares diante do aumento do poder de compra. O objeto de desejo não é mais o alimento abundante, mas o raro; não aquele que enche e faz passar a fome, mas aquele que estimula e convida a comer mais. 24 nesse contexto, a possibilidade de consumo de produtos menos nutritivos pode aparecer associada à dimensão afetiva, isto é, oferecer o que não é fundamental para a alimentação traduz-se para pais e filhos em demonstração de afeto. 20

Outro aspecto remete a sociedade do consumo e a globalização onde a ascensão social apresenta-se como uma oportunidade de deslocamento do espaço alimentar familiar para espaços externos, onde a alimentação torna-se individualizada e isolada. A cozinha materna e os hábitos alimentares da família correm o risco de perder a importância na formação do gosto. 26

Categoria 3. Subjetividade e Crenças 
em torno do comer

Desde as perspectivas em torno da noção de saciedade, até o próprio lugar ocupado pelo alimento na vida de cada sujeito, percebem-se diferentes formas de subjetivação individuais, corroborando para uma visão de comer permeada por vivências singulares, ressaltada na seguinte fala:

Sujeito 1: Hoje eu como para viver, antes eu vivia para comer. é uma frase que eu busquei de força e de incentivo para eu começar essa minha mudança de vida, porque antes eu me enchia de comida e não ficava saciada, parece que eu comia e ficava um vazio em mim. E agora eu como bem menos e fico saciada, eu acho que foi mais uma mudança e um apoio psicológico que eu tive, que eu nunca frequentei uma, nunca tive um apoio psicológico e na minha família a base dela mesmo, assim, não tinha esse preparo para me ajudar a diminuir...

$\mathrm{O}$ caráter histórico-social que define o comportamento alimentar de um sujeito desloca a comida do âmbito simplesmente nutricional, tornando o comer um ato social, constituído de atitudes, ligadas aos usos, costumes, protocolos, condutas e situações. Dessa forma, afirma-se que nenhum alimento que entra em nossas bocas é neutro, podendo revelar crenças, memórias e significados. 27

Ao estudar a Sociologia da Refeição, Simmel28 afirma que "De tudo o que os seres humanos têm em comum, o mais comum é que precisam comer e beber". Mas mesmo diante desta generalização, a rotina alimentar revela também as especificidades características de cada espaço social, o comum torna-se então o próprio, estimulando a distinção e o pertencimento.

A comida assume um espaço, uma função e pode revelar uma vulnerabilidade, como foi possível observar na fala do Sujeito 6 (paciente pós-bariátrica) ao trazer a maior ingestão alimentar associada à perda da figura paterna:

Sujeito 6: eu acho que eu ganhei mais peso depois que meu pai faleceu, que aí eu comecei mesmo a comer forte. Eu comia normal, que nem era esse normal exagerado, mas depois que meu pai faleceu eu fiquei mais triste, aí eu comecei a comer...
As falas revelam a representação da vivência alimentar com um papel que vai além da sensação de saciedade, de uma necessidade orgânica de nutrientes, mas como uma forma de preenchimento de um vazio subjetivo, de alcançar a completude. Numa perspectiva psicológica e comportamental,

o modo de

\section{comer revela a}

personalidade e

o caráter de um

indivíduo [...] quanto mais eu comia, mais eu sentia fome [...]

Também para o Sujeito 3, que revela a utilização da comida como redutora da ansiedade vivenciada:

Sujeito 3: [...] se eu tenho um negócio assim, aí diz assim, 'tal dia eu vou te dar um negócio', aí eu fico ansiosa até chegar esse dia, aí fico comendo (...) Eu fico beliscando (Risos)... é uma bolacha, biscoito, banana (...) é assim quando eu estou ansiosa, eu fico catando coisa e comendo.

As falas revelam a representação da vivência alimentar com um papel que vai além da sensação de saciedade, de uma necessidade orgânica de nutrientes, mas como uma forma de preenchimento de um vazio subjetivo, de alcançar a completude. Numa perspectiva psicológica e comportamental, o modo de comer revela a personalidade e o caráter de um indivíduo24, mostrando que os seres humanos não se alimentam apenas de nutrientes, mas também de símbolos e representações que atribuem aos alimentos que consomem.26

A análise da prática alimentar como um todo, envolve a seleção, o consumo, a produção da refeição, o modo de preparação, de distribuição, de ingestão. No âmbito familiar, estas práticas são oriundas de conhecimentos, vivências e experiências, construídas a partir das condições de vida, da cultura, das redes sociais e do saber científico de cada época histórica e cultural; além de sofrerem influências de diferentes dimensões: temporal, de saúde e doença, de cuidado, afetiva e econômica.29

Todos os critérios que constituem a definição de prática alimentar entonam seu caráter simbólico, ao mesmo tempo que o sujeito revela em si, através de seu corpo, seus aspectos concretos. Os desejos, as satisfações, insatisfações e contradições expressam-se no corpo e a obesidade aparece como um sintoma.30 As questóes individuais, muitas vezes ocultas para outros, revelam-se no lugar mais visível, o corpo, a parte do sujeito que é primeiramente apresentada para o mundo nas interações sociais, perspectiva trazida no estudo de Pinto31.

Categoria 4. Concepções acerca da Obesidade 
Assim como o comer, o próprio ganho de peso e o diagnóstico de obesidade foram trazidos pelos sujeitos como características que adentram na realidade subjetiva de forma singular. Os discursos trazem o significado das mudanças na autoimagem e no quadro de saúde geral, entonando as limitações e uma perda de identidade entre quem se era no passado e quem se é agora:

Sujeito 2: Eu acho que quando a gente perde as condições de praticar um esporte, de fazer um exercício, você não se sente bem consigo nem... vamos dizer, você olha para uma pessoa magra ou de um certo peso que consegue fazer coisas que você não consegue, devido aqueles quilos a mais, aí você se sente mal, viu?

A demanda atual reflete a necessidade da busca pelo belo, mais magro, mais perfeito, pela possibilidade; enquanto a obesidade parece refletir no discurso dos sujeitos a limitação, a perda, o não conseguir mais, gerando sensação de mal-estar frente às cobranças.30

Diante dos padrões exigidos por uma sociedade que se preocupa em cultivar a juventude, a beleza, o corpo saudável e a boa forma, a gordura adquire status de doença,32 sendo interiorizada pelos sujeitos como algo que deve ser tratado, principalmente nos casos de obesidade, gerando comorbidades que se projetaram nas vivências diárias dos sujeitos, como observamos na fala a seguir:

Sujeito 7: (...) é uma doença a obesidade, porque se obesidade fosse coisa boa não precisava se tratar, né? e ela reflete na saúde, todo mundo que eu conheço e está acima do peso dói coluna, dói joelho, é hipertenso, é diabético, sempre tem alguma coisa.

Sendo assim, quando a obesidade assume a definição de doença, buscam-se formas de reversão, geralmente a partir da convocação da medicina que será responsabilizada para o alcance da cura.33 Tal processo desloca, por vezes, do sujeito a implicação sob seu adoecer, excluindo gradativamente sua subjetividade.33 Ressalta-se, então, a importância de resgatar esse sujeito como protagonista de seu processo, revelando as especificidades de seu adoecimento e do histórico de seu comportamento alimentar.
A singularidade das vivências, entretanto, revela também influências familiares

\section{Diante dos padróes} exigidos por uma sociedade que

se preocupa em cultivar a juventude, a beleza, o corpo saudável e a boa

forma, a gordura adquire status de doença, 32 sendo interiorizada pelos sujeitos como algo que deve ser tratado, principalmente nos casos de obesidade, gerando comorbidades que se projetaram nas vivências diárias dos sujeitos [...

elaboradas pelos sujeitos como significativas no processo de adoção de seus compor- tamentos alimentares que levaram à obesidade, como é possível observar nas falas a seguir:

Sujeito 1: (...) você tem que alimentar o que seu pai e sua mãe lhe oferece quando você é infância, na adolescência, na juventude... que eu fiquei lá até os meus 26 anos morando com ele, e, assim, vai pela educação que eles não tiveram, meu pai é analfabeto, minha mãe... e eles não tinham a mente que sabia que a obesidade poderia levar à morte, não tinha essa consciência de obesidade lhe deixa seu corpo todo inflamado, é... a obesidade provoca várias doenças(...) eu acho que se os pais pudessem ter a consciência de educar o filho desde o colo, saber qual é a alimentação certa, influenciar um exercício físico, orientar uma boa alimentação, acho que poderia não desenvolver obesidade numa vida adulta.

A partir desta fala, percebe-se a importância da intervenção clínica da obesidade numa lógica transgeracional, 34 junto às famílias e aos sujeitos, visando minimizar a prevalência da obesidade e, consequentemente, a necessidade de adoção de medidas interventivas de grande porte. Também se ressalta a demanda cada vez mais abrangente, da implementação de medidas de promoção e prevenção à saúde, atendendo de forma integral os indivíduos e suas famílias. 35

\section{CONCLUSÕES}

Neste estudo, foi possível observar que nos discursos e comportamentos dos sujeitos se expressam as vivências familiares e suas influências. As dinâmicas de gênero, os processos de preparação da comida e as relações interpessoais denotam os processos de interiorização, repetição e rupturas predeterminadas pelas experiências passadas dentro dos meios de convivência. As influências familiares, entretanto, unem-se à individualidade construindo concepções e crenças em torno dos hábitos alimentares, denotando o caráter simbólico da comida e seu papel na vida de cada sujeito, adicionando subjetividade e afetividade à esta forma de nutrição. Além dos aspectos simbólicos da alimentação, a historicidade e os mode- 


\section{REFERÊNCIAS}

1. Brasil. Ministério da Saúde. Vigitel Brasil 2019: vigilância de fatores de risco e proteção para doenças crônicas por inquérito telefônico. Brasília, DF; 2020. [Acesso em: 19 jun. 2021] Disponivel em: https:// bvsms.saude.gov.br/bvs/publicacoes/vigitel_brasil_2019_vigilancia_fatores_risco.pdf

2. WHO (World Health Organization). Obesity and overweight. [Acesso em: 21 jun. 2021]. Disponivel em: http://www.who.int/mediacentre/factsheets/fs311/en/

3. Pacheco SSM, Freitas MCS, Fontes GAV, Oliveira N. O hábito alimentar enquanto um comportamento culturalmente produzido. In: Freitas MCS, Fontes GAV, Oliveira N, organizadores. Escritas e narrativas sobre alimentação e cultura. Salvador: Edufba, 217-238; 2008.

4. Góes JÂW. Hábitos alimentares: globalização ou diversidade. In: Freitas, MCS; 2008.

5. Catania AC. Aprendizagem: comportamento, linguagem e cognição. Porto Alegre: Artes Médicas Sul; 1999.

6. Quaioti TCB \& Almeida SDS. Determinantes psicobiológicos do comportamento alimentar: uma ênfase em fatores ambientais que contribuem para a obesidade. Psicologia USP, 17(4): 193-211; 2006.

7. Ramos M \& Stein LM. Desenvolvimento do comportamento alimentar infantil. Jornal de Pediatria, 76(3): 229-237; 2000.

8. Lakatos, Eva Maria; Marconi, Marina de Andrade. Sociologia Geral. $7^{a}$ edição. São Paulo: Atlas; 2010.

9. Codo W \& Lane S. Psicologia Social: o homem em movimento.São Paulo: Brasilie; 1984.

10. Garcia RWD. Práticas e comportamento alimentar no meio urbano: um estudo no centro da cidade de São Paulo. Cad. Saúde Públ, 13(3): 455-467; 1997.

11. Rossi A, Moreira EAM, Rauen, MS. Determinantes do comportamento alimentar: uma revisão com enfoque na família. Rev Nutr, 21(6): 739-48; 2008.

12. Piko BF \& Brassai L. The role of individual and familial protective factors in adolescents' diet control. Journal of health psychology, 14(6): 810-819; 2009.

13. Godoy \& Schmidt, A. Introdução à pesquisa qualitativa e suas possibilidades. Revista de Administração de Empresas. São Paulo, 35(2): 57-63, Mar/Abr; 1995.

14. Gomes R. Pesquisa qualitativa em saúde. São Paulo: Instituto Sírio-Libanês de Ensino e Pesquisa; 2014.

15. Fontanella BJB, Luchesi BM, Saidel MGB, Ricas J, Turato ER, Melo DG. Amostragem em pesquisas qualitativas: proposta de procedimentos para constatar saturação teórica. Caderno de Saúde Pública, 27, 389-394; 2011.

16. Fontanella BJB, Ricas J, Turato ER. Amostragem por saturação em pesquisas qualitativas em saúde: contribuições teóricas. Cad. Saúde Pública; 2008.

17. Silva AH \& Fossá MIT. Análise de Conteúdo: Exemplo de Aplicação da Técnica para Análise de Dados Qualitativos. Qualit@ s Re- vista Eletrônica, 1(1); 2015.

18. Assunção VK. Comida de Mãe: notas sobre alimentação, família e gênero. Repocs, 13(25), jan/jun; 2016.

19. Lévi-Strauss C. O Triângulo Culinário. Estructuralismo y dialéctica. 39-57; 1968.

20. Romanelli G. O significado da alimentação na família: uma visão antropológica. Medicina, Ribeirão Preto, 39(3): 333-339; 2006.

21. Salve JM \& Silva IA. Representações sociais de mães sobre aintrodução de alimentos complementares para lactentes. Acta paul enferm, 22(1): 43-48; 2009.

22. Woortmann K. A comida, a família e a construção do gênero feminino; 1985.

23. Assunção VK. Comida de mãe: notas sobre alimentação e relações familiares; 2012.

24. Montanari M. Comida como cultura. Editora Senac. São Paulo; 2009.

25. Ferreira VA \& Magalhães R. Obesidade e pobreza: o aparente paradoxo. Um estudo com mulheres da Favela da Rocinha, Rio de Janeiro, Brasil. Cad. Saúde Pública, 21(6): 1792-1800; 2005.

26. Moreira SA. Alimentação e comensalidade: aspectos históricos e antropológicos. Ciência e Cultura, 62(4): 23-26; 2010.

27. dos Santos CRA. A comida como lugar de história: as dimensões do gosto. História: questões \& debates. Editora UFPR, Curitiba, 54(1): 103-124, jan/jun; 2011.

28. Simmel G. Sociologia da Refeição. Estudos Históricos, Rio de Janeiro, 33: 159-166; 2004.

29. Domínguez-Vásquez P, Olivares S, Santos JL. Influencia familiar sobre la conducta alimentaria y su relación con la obesidad infantil. Archivos latinoamericanos de nutrición, 58(3): 249-255; 2008.

30. Varela APG. Você tem fome de quê?. Psicologia Ciência e Profissão, 26(1): 82-93; 2006.

31. Pinto FNF. Autoimagem e obesidade: a realidade e suas crenças. 2015.

32. Rocha LJL, Vilhena JD, Novaes JDV. Obesidade Móbida: quando comer vai muito além do alimento. Psicologia em Revista, Belo Horizonte, 15(2): 77-96; 2009.

33. Vilhena JD, Novaes JDV, Rocha L. Comendo, comendo e não se satisfazendo: apenas uma questão cirúrgica? Obesidade mórbida e culto ao corpo na sociedade contemporânea. Revista Mal Estar e Subjetividade, 8(2): 379-406; 2008.

34. Brazão N \& Santos O. Transgeracionalidade na obesidade infantil. Revista de Endocrinologia, Diabetes e Obesidade, 4(2): 87-94; 2010.

35. do Nascimento FJ, Silva DRF, Barbosa HCBC, dos Santos VF, Martins LM, Luz DCRP. Sobrepeso e obesidade em adolescentes escolares: uma revisão sistemática. Saúde Coletiva (Barueri), 10(55): 2947-2958; 2020. 